\title{
The Language of the Levels: Reflections on the Communication of Collection Development Policy
}

\section{Ross Atkinson}

The collection development policy, as a means to express and systematize guidelines for collection building, fulfills three basic functions: the referential, the generative, and the rhetorical. The division of the policy into subject categories, and the use of "collection levels" (such as those defined in the ALA Guidelines for Collection Development) to rank the collection and the collecting effort for each subject, serves these three functions well. More work needs to be done, however, on defining collection levels and the collecting effort to which they refer. These definitions may be more easily achieved if we begin to view the collection levels as designating varying degrees of two opposing collection strategies: inclusion and exclusion.

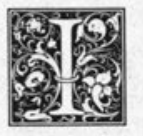

f we understand policies simply as "guides to carrying out an action, ${ }^{\prime 1}$ then there are normally as many selection policies in a library as there are selectors, for each selector necessarily develops, over time, a set of personalized guidelines upon which to base selection decisions. Such policies are usually vague and unarticulated. On the rare occasions when they are written, they are of necessity expressed from the specialized viewpoint of the individual selector. The values upon which such policies are based and the goals toward which they are directed vary, therefore, from one selector to another.

It is the task of the collection development policy to specify, consolidate, coordinate, and adjust such separate selection policies in order to promote the development of a collection that will, as a whole, best respond to the needs of current and future clientele. This task is accomplished by bringing about the translation of the various selection policies into a single language, making adjustments in the individual policies to fit the general collection plan, and then stitching these adjusted policies together into a unified document. While the translation and consolidation reduce the disparity among individual selection policies, it should be noted that such disparity can never-and probably should never-be eliminated entirely. The separate segments of the collection development policy must remain the personal responsibilities and products of individual selectors.

The primary objective of the collection development policy, therefore, is to unify or focus expression concerning the current state and future direction of the collection. If we are to determine how policy works and how to use policy for purposes of collection planning, we need first to understand its operation as a system of communication. This paper is an attempt to move us a step closer to such an under-

Ross Atkinson is assistant university librarian for collection development at the University of Iowa, Iowa City, Iowa 52242.

An earlier version of this paper was read at the RTSD Collection Management and Development Institute, Trinity University, on May 16, 1985. The author wishes to thank Professor Terrence Brooks, School of Library and Information Science, University of Iowa, for helpful criticism of the paper's initial draft. 
standing. It begins with an examination of the general functions of collection development policy, and then turns to a more detailed dissection of the policy's standard structure.

\section{POLICY FUNCTIONS}

Although the functions of collection development policy can be described or defined from a variety of administrative, bibliographical, or epistemological perspectives, the collection policy as a communications device intended to transfer information about the development of a collection fulfills at least three fundamental functions. First, it provides a description of the collection's current state, development, and desired direction. This is the policy's referential function. Second, the policy serves the selector, if only inferentially, as a method or instrument to transform the collection from its current to its desired condition. This is the policy's generative function. Finally, the policy also acts as an argument that there is a systematic collection plan in effect, and that such a plan is worth pursuing. This is the policy's rhetorical function. The referential function is primary; the generative and rhetorical functions derive from the referential function. Let us take a closer look at these three functions.

Like any document, the collection policy fulfills its referential function through the application of a conventionalized system of signs. A sign is a "cultural unit" that "is defined inasmuch as it is placed in a system of other cultural units which are opposed to it and circumscribe it. ${ }^{\prime \prime 2}$ In other words, meaning derives from the relationships among signs. Because such relationships take place entirely within a system, moreover, that system is, to use Umberto Eco's cumbersome term, auto-clarificatory, i.e., "capable of checking itself entirely by its own means." ${ }^{\prime 3}$ The only way to learn the reference or meanings of the signs of which a sign system (such as a language) is composed, therefore, is to make use of that system, contrast its constituent signs with each other, and arrive at an understanding of how those signs relate among themselves.

The core of the standard collection development policy for larger libraries, and increasingly for smaller libraries, ${ }^{4}$ consists of a series of subject categories. The current collection strength, current collecting intensity, and the desired collecting intensity for each subject category are then ranked according to a scale of "collection levels. ${ }^{5}$ These components will be examined in detail when the problem of structure is discussed. The subject categories and collection levels serve as specialized sign systems, the constituent signs of which can only be understood by using those systems and, through such use, contrasting the signs within each system to each other. The referentiality and the effect of the collection policy derive from the use of these systems in conjunction with each other. The collection policy is, therefore, ultimately a self-validating network of relationships; the key to making, writing, and using collection policy is to understand how its constituent elements interrelate.

Turning to the generative function, we should recognize that a successful policy is one that supplies the means to generate, over time, a collection with certain desired properties. The policy must also provide the selector with some insight into the method of achieving such a desired collection state. As a consequence, the collection policy must not only refer to the current and the desired states of the collection but should permit the selector to infer how to transform the collection from the current to the desired state. This complex and problematic area of collection policy has received little attention. Nevertheless, it is clear that a policy that does not fulfill a generative function will have little effect.

Closely linked to the referential and generative functions is the rhetorical function. The purpose of rhetoric is persuasion. The targets are the three audiences of collection policy identified by Eric Carpenter. ${ }^{6}$ First, the policy should show faculty and students that the reasons the library contains certain materials and not others are part of a rational, consistent, publicly announced plan. Second, the institutional administration should be led by the policy to recognize that optimum use is being made of materials funding, and that requests for increased funding derive from a process of sustained and system- 
atic planning. Third, the library's consortia partners should also be moved by the policy to view the collection development operation as stable and reliable, and to accept the possibility of entering into mutually advantageous agreements with clearly defined goals. Within the library the policy fulfills its rhetorical function by demonstrating to selectors that there is indeed a consciously controlled, librarywide collection development system in effect that defines the parameters of their responsibilities.

These three fundamental functions of collection policy are closely related and interdependent. The generative function clearly relies upon the rhetorical function, for merely to provide a method is no guarantee that it will be used. The selector must receive from the policy not simply direction but also the impetus to take that direction into account. Regardless of how thoroughly the selector is convinced of its merit or utility, this direction cannot be followed unless it is intelligible. This is achieved through the network of relationships established by the policy's referential function.

\section{POLICY STRUCTURE}

Over the past two decades, as collection development has become a recognized and distinct library operation, an increasingly standardized structure for collection policy has evolved.? The components of this structure have been summarized and canonized in the ALA Guidelines, ${ }^{8}$ and have been most ably amplified by Charles Osburn. ${ }^{9}$ In its standard form the policy includes introductory material on general objectives, divisions of subject responsibility, and duplication. A glance at the anthology of policies compiled by Elizabeth Futas will confirm the variety and significance of such information. ${ }^{10}$ Indeed, the "analysis of mission, clientele and programatic objectives is a vital prelude to the detailed subject analysis of collection policy." 11 The heart of the policy remains, however, the segmentation of the collection into subjects, and the rating of the quality of each subject segment according to the system of collection levels. ${ }^{12}$ It is to this central component of collection policy that attention needs to be directed.

The core structure consists of two parts: (a) the matrix that is formed by the intersection of the subject classes and three collection aspects, i.e., current collection strength, current collecting intensity, and desired collecting intensity (see figure 1) and (b) the collection levels that serve as a scale for rating the collection aspects for each subject.

Let us begin with an examination of the matrix. Although the collection aspects usually form the vertical columns, and the subject classes the horizontal rows, I have tilted this formation on its side in figure 1 because I feel this enhances our under-

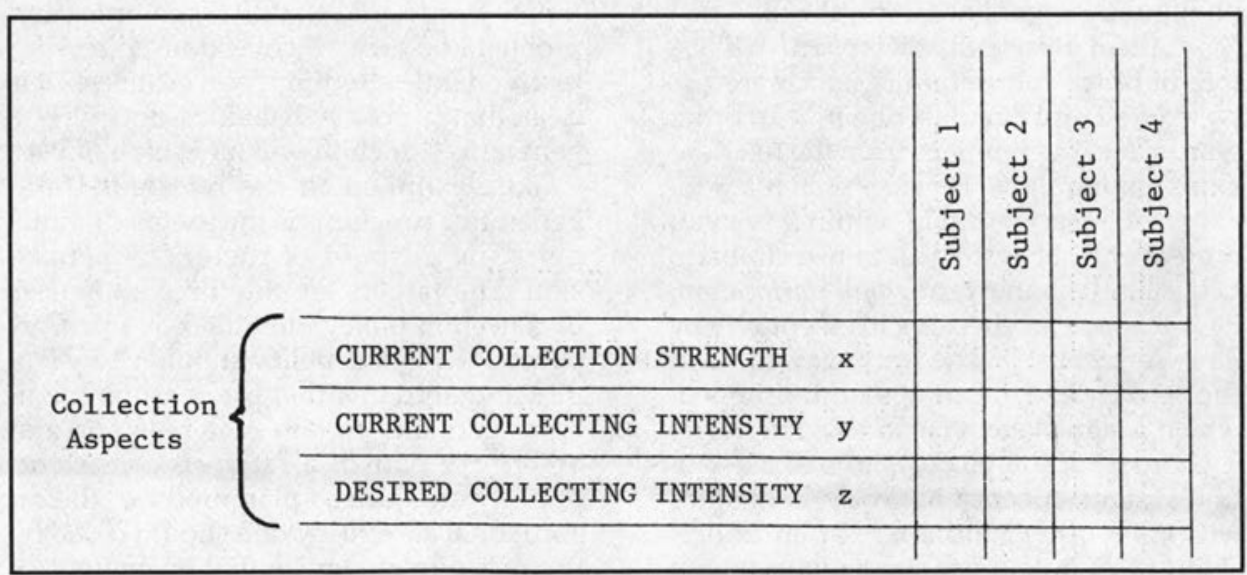


standing of the relationships among the components of the matrix.

Collection policies traditionally categorize subjects according to standard disciplines. It is now becoming common to subdivide these general subjects into smaller topical subjects. The subject classification system to be used and the detail of subject breakdown depend upon such factors as the size and scope of the collection, the publishing rate in the subjects collected, the extent to which the policy is to serve as a basis for cooperation with other libraries, and the sophistication of the policy users.

While a policy without subject categories is not unthinkable, a policy without some kind of collection classification is. In rare cases when a library unit is more concerned with the physical content than the intellectual content of its collection, classification by format could be preferable. It is also conceivable that a policy for some very narrowly defined special collections could be based on imprint or even date of publication. Policies of larger university libraries are usually divided by topical subject, and then further subdivided by categories such as format, geography, or chronology. In any case, the value of classification is not only that it divides the collection into manageable units and creates the opposition necessary for the policy to achieve an appropriate level of reference, but also that it permits reference to segments of the collection without detailed knowledge of the composition of these segments. This is, of course, the distinctly bibliographical use of subject categories.

At the user level subjects are normally understood as subject matter, i.e. as topics of documents. On the bibliographical level, however, that relationship is inverted: subjects are not primarily concepts to which library materials refer, but rather concepts that refer to library materials. Subjects are systems of reference already in place; as such, they function as cumulative titles that permit us to refer not only to groups of materials already held but also to groups of materials that have not yet been created. To be sure, such a prospective application of subject categories depends for its success upon the creativity of the selectors who must determine which concrete titles fit into which abstract categories. This is one reason why it is possible for two libraries with identical collection policies to build different collections.

The other component of the matrix consists of the three collection aspects. Let us label these aspects, following Berkeley, $x$, $y$, and $z .{ }^{13}$ Each of these aspects is to be rated for each subject according to the collection levels. The first $(x)$ is what the Research Libraries Group (RLG) calls "estimated collection strength," and which the ALA Guidelines refer to as "collection density." This represents the current condition of the collection. The second $(y)$, called "current collecting intensity" is the level at which the collection is currently being built. While collection strength is an indication of the level of the subject collection in place, current collecting intensity is a reference to the level at which the collection is presently being developed. The third aspect $(z)$ is what the Guidelines label the "desirable level of collecting."14 The latter category represents the actual " policy judgment." 15 This occurs because policies, as George Steiner and John Miner put it, "are means to ends and, as such, explain what people should do as contrasted with what they are doing. ${ }^{\prime 16}$ Thus $y$ is a statement of what $x$ is evolving into, while $z$ represents a projection of what $x$ should be evolving into. $Z$, is, therefore, the collecting objective. The distance of the library from its objective is represented by the difference between $z$ and $y$, for once the level of $y$ has become the level of $z$, the library is in the process of transforming $x$ into $z$. We are consequently justified in labeling $z$ the "desired collecting intensity."

Some policies, such as Stanford's ${ }^{17}$ or Northwestern's ${ }^{18}$ contain only a value for $z$, while others, such as Berkeley's ${ }^{19}$ and the recent Brown policy ${ }^{20}$ include values for both $x$ and $z$. Berkeley established values for $y$ as well, but these were apparently deleted as out-of-date before the final draft of the policy was completed. ${ }^{21}$ The policy presently being developed by the University of Oklahoma contains values for $x, y$, and $z$. There is, in any case, still some disagreement over the relation- 
ship between $y$ and $z$. In my experience some policymakers seem either to confuse these separate concepts or to think of the term "current collecting intensity" as generally what is being strived for rather than what is actually being achieved.

Before turning to an analysis of the collection levels, something needs to be said about the mechanics of filling in the matrix. This work is normally undertaken by the selector responsible for that subject segment of the collection to which the matrix is referring. Assuming that the selector understands the collection levels-no easy task, as we will see in a momentwhich procedure should the selector follow to apply those values to the collection aspects in order to fill out the matrix?

It is sometimes recommended that the collecting intensity or $y$ be established first, then the estimated collection strength or $x .^{22}$ While this is doubtless a practicable method, it fails to take into account the fundamental relationships between $x$ and $y$. Row $x$ is a string of signs that refers in its cumulation to the current condition of the collection. It is an encrypted description of the collection, using the code of the collection levels. Clearly it must entail some kind of collection evaluation, or a series of evaluations. Whatever method of evaluation is applied, however, the selector must begin by using the evaluation to establish the level at which the collection on a particular subject should be located. This first step is without a doubt the most difficult. It is essentially a matter of expressing the results of the evaluation in the language of the collection levels. In order to do this, the selector completing the matrix must learn the language of collection levels: he or she must decide what the levels symbolize with respect to the particular collection segment. As in any encryption, decryption, or translation process, the first step is necessarily tentative. Gradually, however, contexts are established and judgments can be based increasingly on consistency. Once one cell in row $x$ is filled in, therefore, it can be opposed and compared to another cell in row $x$, and so forth. As one proceeds to complete row $x$, cells filled in earlier will need to be altered in order to conform. Eventually, however, the entire row will form a consistent whole, expressed in the language of the collection levels as a "self-clarificatory" system thoroughly understood by the selector as it relates to the particular collection for which the selector is responsible.

This method of playing off the whole and the part against each other is, of course, a classical concept of interpretation, the so-called hermeneutic circle. In interpreting a text, the whole must reflect its individual parts, and each part must be consistent with the whole. The only problem is that, if one can only understand the whole through the parts and the parts through the whole, there would be no place to start. The solution to this dilemma has traditionally been the so-called "hermeneutic leap." The interpreter must simply begin at some point with some tentative interpretation, and as the interpreter progresses through the text, constantly gauging the parts by the whole and vice versa, and eventually arrives at a selfvalidating interpretation. ${ }^{23}$ This is also the only reliable method to establish a systematic description of collection strength using the language of the collection levels. A primary purpose of row $x$, then, is to provide the selector with the possibility and the opportunity to learn the language of the collection levels.

The next step is to complete row $y$. From the standpoint of interpretation, this is much easier than completing row $x$, because the code has, so to speak, already been broken. While row $x$ is filled out horizontally (in figure 1), row $y$ should initially be compared with the cell above it in row $x$. In each case the selector needs simply to ask: Given those qualities of the collection as signified by the language of the collection levels in row $x$, how are my current selections affecting those qualities?

The final step in filling out the matrix is the completion of row $z$, which involves the actual formulation of policy. This row is best completed by the collection development officer working with the selector who completed rows $x$ and $y$. (The collection development officer is the administrator responsible for the library's overall collection policy. This person may also 
serve as a selector.) Thus rows $x$ and $y$ supply data that contribute to the policy decisions to be represented in row $z$.

Other data needed in making such policy decisions (in addition, obviously, to a full assessment of the bibliographic needs of current and future clientele) are the qualities of other collections expressed in the same language so that collection sharing agreements can be established. This is, of course, the rationale behind the Conspectus: ${ }^{24}$ it assists policymaking in that it provides an intelligible indication of whether the qualities of collections in other libraries might make possible an arrangement whereby libraries can rely on each other's collections for certain subjects. It should be noted, however, that such descriptions of collections in other libraries using the same language of collection levels will not help the individual selector to learn that language; having access to policies of other libraries will not, in other words, assist the selector to complete row $x$, because the selector is not normally acquainted with the detailed characteristics of those collections in other libraries. The selector cannot, therefore, know how the levels refer to the collection qualities of other libraries. One purpose of the verification studies in RLG has been to provide its members with some insight into the characteristics of each other's collections in order to assist in the completion of the Conspectus.

The collection development officer needs a general understanding of the language of the collection levels, both to ensure that the language is being used consistently and to understand the collection policies of other libraries. But as in the case of selection, the collection development officer must rely upon the special knowledge and integrity of the selector. The collection development officer makes policy by deciding whether the current collecting intensity, as expressed in row $y$, should be raised, lowered, or left the same in row $z$. The collection development officer must assume that the values expressed in rows $x$ and $y$ are accurate, but need not know precisely how the value in rows $x$ and $y$ refer to the detailed qualities of the collection. Indeed, the collection development officer cannot have such precise and detailed knowledge without having participated in the evaluation and language learning achieved by the selector in completing row $x$.

This is why the collection development policy represents the fusion of a series of individual selection policies. The language of the levels permits communication because we have agreed among ourselves that the signs composing that language stand for certain abstract collection attributes. However, each selector in using such signs to describe a collection will necessarily understand those signs differently from other selectors. Ambiguity deriving from individuality of use is common to most languages; the language of the collection levels is no exception.

The collection development officer normally knows only the abstract definitions of the collection levels such as appear in the Guidelines and makes policy accordingly. But the selector must carry out that policy. When the collection development officer determines that the library needs to develop a four-level collection, say, in fluid mechanics, the selector must decide what that means. This is not simply in the sense of abstract definitions but from the standpoint of actual titles. The selector is able to do this because he or she has already learned the meaning of the language of the collection levels with respect to the particular collection by completing row $x$ in the policy. Without that knowledge, the plans represented in row $z$ would mean very little.

All meaning derives from relationships: If you don't know where you are, you don't know where you are going, because where you are going is understandable only in relation to where you are. $Z$ (where you want to go) and $y$ (where you are going) are only understandable as relationships to $x$. This is why $x$ is an essential part of any policy. The inclusion of $x$ is, moreover, vital not only for referential purposes but also for the fulfillment of the policy's generative function. Only by including $x$, and only by using the same language to describe $x$ as is used to describe $y$ and $z$, does the method of transforming the collection from $x$ to $z$ become conceiv- 
able and expressable for the selector.

\section{THE COLLECTION LEVELS}

The levels of $A-E$ in the ALA Guidelines, used in part by the RLG and the Association of Research Libraries as 5-0, are fast becoming the standard means to describe collections. ${ }^{25}$ The levels have been the source of controversy, because they have been designed for academic libraries, or more specifically, for large research collections. ${ }^{26}$ Smaller libraries have adapted the definitions to their needs by subdividing the two- and three-levels where the bulk of their collections fall. Subdividing can be useful. Care must be taken, however, to ensure that the divisions between the broader collection levels (especially between levels two and three) remain intact. Otherwise these adaptions may create separate languages. When this happens the levels can no longer serve as a means of communication among libraries.

In spite of the criticism and the adaptations and permutations of the levels, to my knowledge there has been no effective challenge to the use of levels to formulate collection development policy. The essential question, therefore, is not how the levels are being adjusted but rather to what the levels refer or what they permit us to scale.

Let us examine the collection levels as a scale. The primary function of all scales is representational: the relationships among the calibrations on the scale are intended to represent the relationships among the properties of the scaled object. ${ }^{27}$ But some scales are clearly more representational than others. Using the traditional classification of scales as defined by S. S. Stevens, ${ }^{28}$ it is apparent that the collection levels constitute an ordinal scale that "presupposes a natural rank-ordering of objects with respect to some property.,"29 The collection levels as an ordinal scale, therefore, must rank order some property of collections. But what is this property?

It is a mistake to imagine that the property we are seeking is equivalent to what we have been referring to as the collection aspects. This would tell us nothing. We do well to recall that much of the language we use to talk about information consists of metaphor. ${ }^{30}$ This is especially true of col- lection development in which we rely heavily on such metaphors as density, intensity, strength, breadth, depth, and scope. These metaphors stand for a multitude of inferred qualities that we never seem to delineate. Just what do we mean by a strong collection? Is it a collection that approaches the unattainable comprehensive collection? Or is it the one that users agree is the most useful? Or is it one that librarians define as the strongest on the basis of evaluation-and if so, which method of evaluation?

It is apparent that the collection levels on an ordinal scale must represent some quantitative relationships. Because the levels are often considered to be progressively inclusive-a four-level collection, for example, is often thought to contain within it a three-level collection-such a quantitative relationship among levels is unavoidable. The range of the scale also presupposes quantitative relationships, because the scale runs from a condition of trying not to collect anything on a subject to one of trying to collect everything on a subject. The levels represent distances from those extremes.

To view the collecting levels merely as successive stages of a continuum or merely as an ordinal scale, however, restricts our ability to perceive their full range of referentiality. One can conceive of the collection levels with the two ends of the scale understood not so much as stable points like top and bottom or strong and weak but rather as strategic directions toward which selection efforts can progress. Such a directional view implies that the levels need not be separate and distinct but can overlap. These two directions are labeled inclusive and exclusive in figure 2. Both the inclusive and the exclusive goals are absolutes and are unattainable in reality. If one cannot build a comprehensive collection, one cannot also for the same or similar reasons build a zero-level collection.

Probably the most significant characteristic of the collection directed toward the inclusive objective is the increasing blur between quantity and quality. For research collections, quantity eventually becomes quality. In the language of Hegel, there is a nodal line, i.e., "a point in ... 
quantitative change in which Quality changes. ${ }^{\prime \prime 11}$ When a collection increases in size beyond a certain critical mass, the collection's quality also improves-at least from the inclusive perspective. It is, moreover, important to recall that the use of collection levels for policy purposes has until recently been restricted to large research libraries where quality is necessarily viewed in a relatively quantitative fashion. This is why we may be inclined to view the collection levels as primarily quantitative.

As we move toward the exclusive goal, the distinction between individual items becomes increasingly important. Quality is defined to a great extent by use. Eventually, at the far end of the exclusive direction, demonstrably high use becomes the sole basis for selection. Exclusively oriented collections thus place the main emphasis on use value, while inclusively oriented collections subscribe to a system that may be viewed as something closer to exchange value. This does not mean that utility is not important for large libraries. In libraries as in commerce, use value is a precondition for the consumption of products by the public. It is only toward the inclusive end of the scale that the individual documents held by a library become increasingly interchangeable as members of the theoretical class of all materials on the subject that the comprehensive level symbolizes.

The dichotomy between inclusion and exclusion also affects collection assessment. For collections inclined toward exclusion, use and user studies, or some types of citation analysis, probably provide the most effective method of evaluation. For collections aimed at inclusion, more quantitative methods of assessment would be more effective such as shelf-list counts or the list-checking method. ${ }^{32}$ RLG relies heavily on the list-checking method for its verification studies.

The exclusion-oriented collection emphasizes currency and depends-or should depend-on weeding. The policy of such an exclusively directed collection should therefore provide special guidelines for deselection. The inclusively oriented collection emphasizes historicity and requires guidelines applicable to ret- rospective selection and preservation.

The orientation of the collection also affects language, format, date of publication, and place of publication. These are all special features of documents and become increasingly important toward the exclusive end of the scheme. The more one moves toward that end, the more useful these qualities become as excluding devices. On the other hand, the closer one moves to the inclusive end, the less vital these matters become. As one approaches the ideal state of absolute comprehensiveness only found in special collections, one acquires material on the subject regardless of when or where it was published, or of the format or language in which it was published.

A final advantage to taking a more dichotomous view of the collection levels is the insight that it may permit into another dimension of collection value: the degree of selection effort involved in building different kinds of collections. Part of the reason for making policy is to know the amount of total resources-including the work of selectors-required for collection building. This is necessary because part of the value of anything produced for the consumption of others must be determined by the labor needed for its production.

The $b$-axis in figure 2 , represents collection effort. It is possible to construct a $2+$ collection with macrodecisions alone. By developing a vendor profile, designating relevant subjects and standard publishers, a $2+$ collection can be built more or less automatically. As one moves toward either end of the scale, however, collection effort increases. The labor intensity of selection becomes greater in approaching the inclusive end, because the selector expends ever greater energy in searching out material not easily available or widely known. As one approaches the exclusive end, labor intensity also increases as the selector must have more rigorous criteria to justify avoiding selection and for predicting that a given item will have high use.

By taking such a two-dimensional view of the collection level as depicted in figure 2 , it is possible to factor into collection policy a more unified reference to the cost in 


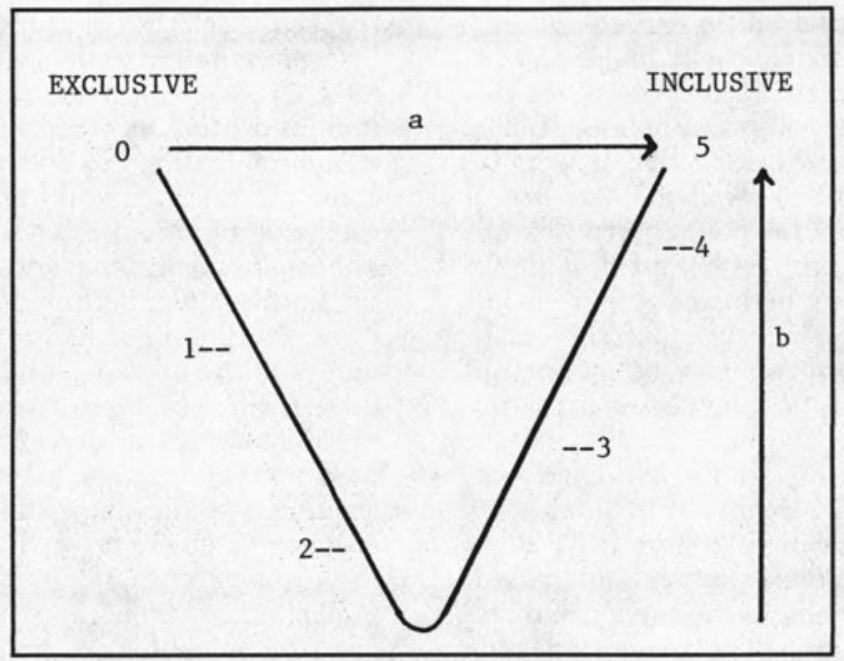

FIGURE 2

The Collection Levels

human resources. One can then consider axis $a$ as representing the materials costs, and axis $b$ as representing the personnel costs necessary for collection building.

\section{CONCLUSION}

It is clear that to view the collection levels merely from the standpoint of what they denote as an ordinal scale severely limits our ability to understand the full extent of the policy's content. While the levels may denote quantitative distinctions, they connote much more concerning the relative values and methods that effect the development of different types of collections. Ultimately, it is the connotations that contribute most substantially to the policy's essential functions. By mastering the connotations of the collection levels the selector can use the levels to refer to the special qualities of the appropriate collection segment. By means of such connotations the selector is also encouraged to draw conclusions about the processes necessary to transform a collection from one state to another. Even the rhetorical function is served in this way, because in establishing such connotations the selector is obliged to invest time and thought, and this participation should contribute to the selector's acceptance of the value of the policy. If we intend, therefore, to improve our understanding of the use and potential of collection policy, it is essential that we devote more attention to unraveling the complex and subtle network of relationships that constitute the policy as a system of communication.

\section{REFERENCES AND NOTES}

1. George A. Steiner and John B. Miner, Management Policy and Strategy: Text, Reading and Cases (New York: Macmillan, 1977), p.24.

2. Umberto Eco, A Theory of Semiotics, Advances in Semiotics (Bloomington, Ind.: Indiana Univ. Press, 1976), p.73.

3. Eco, Theory of Semiotics, p. 68.

4. Elizabeth Futas, ed., Library Acquisition Policies and Procedures, 2d ed. (Phoenix: Oryx, 1984), p.435.

5. David L. Perkins, ed., Guidelines for Collection Development (Chicago: American Library Assn., 1979), p.3-5, defines five collection levels: A (Comprehensive), B (Research), C (Study), D (Basic), and $\mathrm{E}$ (Minimal).

6. Eric J. Carpenter, "Collection Development Policies: The Case For," Library Acquisitions: Practice and Theory 8:44 (1984). 
7. Marion L. Buzzard, "Writing a Collection Development Policy for an Academic Library," Collection Management 2:323 (Winter 1978).

8. Guidelines, $1-8$.

9. Charles B. Osburn, "Planning for a University Library Policy on Collection Development," International Library Review 9:209-24 (Apr. 1977).

10. Library Acquisition Policies and Procedures, p.435.

11. Sheila T. Dowd, "The Formulation of a Collection Development Policy Statement," in Collection Development in Libraries: A Treatise, ed. Robert D. Stueart and George B. Miller, Jr. (Greenwich, Conn: JAI Pr., 1980), p.73.

12. Charles B. Osburn, "Some Practical Observations on the Writing, Implementation, and Revision of Collection Development Policy," Library Resources \& Technical Services 23:10 (Winter 1979).

13. Dorothy A. Koenig, "Rushmore at Berkeley: The Dynamics of Developing a Written Collection Development Policy Statement," The Journal of Academic Librarianship 7:346 (Jan. 1982).

14. Guidelines, p.7.

15. Dowd, "Formulation," 78; Koenig, "Rushmore," p.346.

16. Steiner and Miner, Management Policy, p.25.

17. Paul H. Mosher, The Libraries of Stanford University: Collection Development Policy Statement (Stanford, Calif.: Stanford Univ. Libraries, 1980).

18. Richard L. Press, An Acquisition Policy for the Northwestern University Library Evanston Campus, rev. ed. (Evanston, Ill.: Northwestern Univ. Library, 1972).

19. Dorothy Koenig and Sheila Dowd, Collection Development Policy Statement, prelim. ed. (Berkeley, Calif.: The General Library, Univ. of California, 1980).

20. Brown University Library Collection Development Policy (Providence, R.I.: Brown Univ. Library, 1984).

21. Koenig, "Rushmore," p.346.

22. Jutta Reed-Scott, Manual for the North American Inventory of Research Library Collections (Washington, D.C.: Assn. of Research Libraries, 1985), p.35.

23. Richard E. Palmer, Hermeneutics: Interpretation Theory in Schleiermacher, Dilthey, Heidegger, and Gadamer, Northwestern University Studies in Phenomenology \& Existential Philosophy (Evanston, Ill.: Northwestern Univ. Press, 1969), p.87.

24. Nancy E. Gwinn and Paul H. Mosher, "Coordinating Collection Development: The RLG Conspectus," College and Research Libraries 44:136-37 (Mar. 1983).

25. RLG Collection Development Manual, 2nd ed (Stanford: The Research Libraries Group, 1981), p. "2-1"-"2-2." RLG level 5 is equivalent to level A (Comprehensive) in the ALA Guidlines, RLG level 4 is equivalent to ALA level B (Research), etc. See also Reed-Scott, Manual, p.14-16.

26. Rose Mary Magrill and Doralyn J. Hickey, Acquisitions Management and Collection Development in Libraries (Chicago: American Library Assn., 1984), p. 25.

27. See Ernest W. Adams, "Measurement Theory," in Current Research in Philosophy of Science, ed. Peter D. Asquith and Henry E. Kyburg, Jr. (East Lansing, Mich.: Philosophy of Science Assn., 1979), p.208.

28. S. S. Stevens, "On the Theory of Scales of Measurement," Science 103:677-80 (7 June 1946).

29. Karel Berka, "Scales of Measurement: A Critical Analysis of the Concept of Scales and of their Function in the Theory of Measurement," in Language, Logic, and Method, ed. Robert S. Cohen and Marx W. Wartofsky, Boston Studies in the Philosophy of Science, 31 (Dortrecht: Reidel, 1983), p.18.

30. See Patrick Wilson, Second-hand Knowledge: An Inquiry into Cognitive Authority, Contributions in Librarianship and Information Science, 44 (Westport, Conn.: Greenwood, 1983), p.3-10.

31. Hegel's Science of Logic, trans. W. H. Johnston and L. G. Struthers (New York: Macmillan, 1929), p.387.

32. The best current synopsis of evaluation methods is Paul H. Mosher, "Quality and Library Collections: New Directions in Research and Practice in Collection Evaluation," Advances in Librarianship 13:211-38 (1984). 